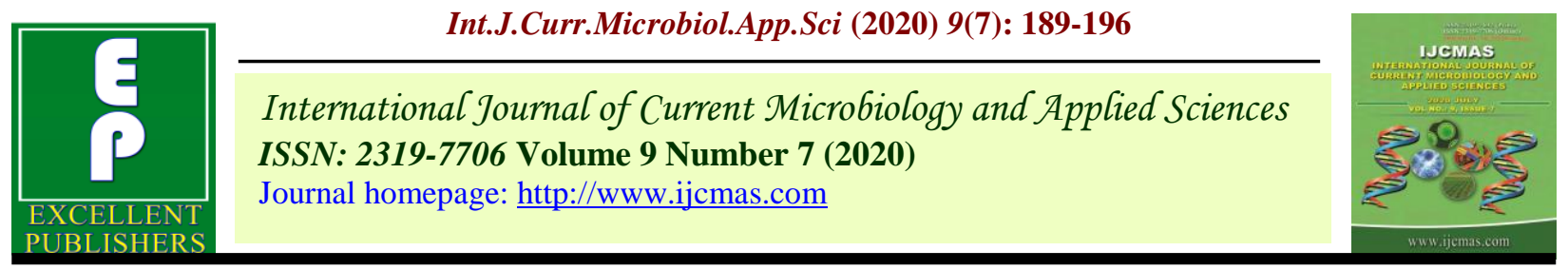

Original Research Article

https://doi.org/10.20546/ijcmas.2020.907.022

\title{
Comparative Evaluation of Rapid Crossing Techniques for Wheat x Maize System of Doubled Haploid Production
}

\author{
Gagandeep Singh, Puja Srivastava and G. S. Mavi* \\ Wheat section, Department of Plant breeding \& Genetics, PAU, Ludhiana, India \\ *Corresponding author
}

\begin{tabular}{|l|}
\hline Ke y w o r d s \\
Wheat, maize, \\
$\begin{array}{l}\text { Plastic bag, } \\
\text { clipped glume }\end{array}$ \\
\hline Article Info \\
\hline $\begin{array}{l}\text { Accepted: } \\
\text { 05 June } 2020 \\
\text { Available Online: } \\
\text { 10 July } 2020\end{array}$ \\
\hline \hline
\end{tabular}

\begin{abstract}
A B S T R A C T
Five different emasculation methods viz. standard technique for wheat $\mathrm{x}$ maize crosses, early pollinations on non-emasculated spikes, clipped glume facilitated emasculation, plastic bag emasculation and hot water emasculation were compared. Clipped glume facilitated emasculation resulted in lowest caryopses formation frequency. Early pollination on non-emasculated spikes gave reasonably high embryo formation frequency while omitting tedious emasculation steps. An innovative method based on non-dehiscence and functional sterility of anthers exposed to high humidity in plastic bag showed good promise though considerable proportion of selfed seed $(32.99 \%)$ was observed. The method that proved best involved hot water $\left(43^{\circ} \mathrm{C}\right.$ for $\left.4 \mathrm{~min}\right)$ treatment of detached tillers. It showed high embryo formation frequency $(30.88 \%)$ and low selfed seed set $(3.20 \%)$. Some level of female sterility observed in this method is needed to be tackled through further refinement.
\end{abstract}

\section{Introduction}

Derivation of homozygous lines from crosses is a primary plant breeding process, which conventionally involves 5-6 generations of selfing and is considered a major time consuming step in varietal development. Doubled haploids (DH) offer a way of overcoming this bottleneck by achieving complete homozygosity in a single step. Besides saving time, doubled haploids allow for greater efficiency of selection compared to early segregating generations on account of exclusively additive nature of variation and simplification of the segregation pattern. For instance, the recovery of a specific homozygous recombinant from $\mathrm{x}$ independently segregating loci is $2^{\mathrm{x}}$ times more efficient than with conventional genetic methods (Jensen 1977).

The wheat $\mathrm{x}$ maize approach of doubled haploid production (Laurie and Bennett 1986), is finding use in public and private sector wheat breeding programmes in Australia, US, Japan and several other countries (Kuchel et al., 2005). This system of $\mathrm{DH}$ production is also serving to generate 
populations for genetic analysis and gene mapping. The DH approach is particularly useful for genetic studies and breeding of complex traits as fixed (homozygous) genotypes amenable to multiple and precise evaluations are available at every recombination step. The applicability of the approach is however largely dependent on capacity to produce DH in numbers which are adequate for breeding purposes. The time saved in the breeding process cannot be at the cost of thorough exploration of the recombination potential. Thus for practical utility, bottlenecks to a scaled up DH production must be removed.

A major step in wheat DH production, which needs to be addressed in this regard is emasculation of wheat spikes for crosses with maize. Unlike the 3 to 4 ears used in wheatwheat hybridization (for breeding purposes), hundreds of ears per cross have to be pollinated with maize for $\mathrm{DH}$ production. While the former is aimed at producing a single $\mathrm{F}_{1}$ genotype, the latter is meant to represent the segregation spectrum of a cross. Moreover, even optimal frequencies of fertilization (e.g., 25-30\%), plant regeneration and chromosome doubling steps in wheat $\mathrm{x}$ maize crosses, render a significant proportion of pollinations ineffective.

The necessity of using large number of ears in wheat $x$ maize crosses encounters a formidable constraint in the tediousness and labour intensiveness of the emasculation process. Further, in deference to adequate caryopsis health in this wide cross, the glumes are generally not clipped and as a result the pollination becomes as time-consuming as emasculation.

Emasculation and pollination keeping glumes intact thus represents the control or benchmark procedure. The time and labour saving alternatives that have been reported mainly include clipping of glumes, bypassing of emasculation followed by sorting of selfed and crossed caryopsis and hot water treatment for rendering wheat anthers ineffective. The present study makes a comparative evaluation of these methods in terms of caryopsis and embryo formation frequency in order to offer viable alternatives that permit greater use of DH approach in wheat breeding. Importantly this evaluation was carried out in the context of DH production using detached wheat tiller culture, which offers major advantages of extending the window of operation and allowing low cost environment control of pollination and post-pollination events.

\section{Materials and Methods}

Field grown $\mathrm{BC}_{1} \mathrm{~F}_{1}$ plants of wheat cross $\mathrm{HD}$ 2967/ Excalibur // HD 2967 were used for DH production, employing different emasculation methods. As in regular crossing technique, the central florets were removed, targeting the emasculation methods to the better and uniformly developed primary or outer florets of each spikelet. The following emasculation methods were evaluated:

\section{Standard technique for wheat $\mathrm{x}$ maize crosses}

Central florets are removed as in conventional wheat crosses but primary florets are not clipped to expose the anthers for emasculation. Emasculation is performed on primary florets by parting the intact lemma and palea with forceps and carefully plucking out the anthers. While this operation is performed on ears on the plant, pollination is carried out indoors on detached tillers. Pollinations in the standard technique involve parting of lemma and palea again for depositing the maize pollen on the feathery stigma. This procedure generally requires joint handling by two workers. 


\section{Early pollinations on non-emasculated spikes}

This method differs from the standard method in two respects. First, the anthers are not removed and second, that pollination with maize pollen is performed 24-48 hours before expected anthesis in the unemasculated spike.

\section{Clipped glume facilitated emasculation}

This is the method generally followed for wheat $\mathrm{x}$ wheat crosses. Lemma and palea are clipped back to about $50 \%$ of their length, in order to expose the anthers and facilitate their removal. Pollinations are performed, as in all other techniques studied, on detached tillers.

\section{Hot water emasculation}

In this case tillers to be used were detached from field grown plants one day prior to anthesis. Central florets were removed before this step. Hot water treatment of spikes was given by directly immersing small batches of the unemasculated spikes for four minutes in water held at $43^{\circ} \mathrm{C}$ in a water bath. Pollinations on these detached tillers maintained in culture media were performed 24-48 hrs after hot water treatment.

\section{Plastic bag emasculation}

After removal of central florets as well as immature spikelets at the tip and base of the ear, tillers with unemasculated spikes were detached from the plant, one to two days prior to anthesis. Small batches of ears were covered with a transparent plastic/polythene bag in an air tight manner by securing the bag with a thread at the base of the ears. The protruding stems reached into the tiller culture medium. Pollinations were performed after almost all the florets showed extrusion of non-dehisced anthers. The extruding anthers were shed by shaking the bouquet of ears along with the bag. Bag was removed prior to pollination with maize. While three of the methods were used in 2014-15 crop season at Punjab Agricultural University, Ludhiana, Punjab (India) all five were taken up during the off season of 2015 at Keylong, Himachal Pradesh (India). In each of the emasculation methods, pollinations were performed with freshly collected maize pollen. Pollinated tillers were maintained for 15 days on tiller culture medium containing Murashige and Skoog (1962) basal salts, $40 \mathrm{~g}$ sucrose per liter and $8 \mathrm{ml}$ sulphurous acid per liter.

Caryopses obtained from tillers were surface sterilized using $0.1 \% \mathrm{HgCl}_{2}$ for 8 minutes in laminar flow and washed with autoclaved distilled water. Caryopses were again washed in $90 \%$ ethanol for 2 minutes in laminar flow. After final washing with autoclaved distilled water caryopses were dissected to rescue haploid wheat embryos which were placed on MS salts based plant regeneration media containing $20 \mathrm{~g}$ sucrose per liter.

With respect to different emasculation techniques, each treatment was replicated two times. Observations were recorded on caryopsis formation frequency $(\%)$, that is, number of caryopsis formed per 100 florets pollinated and embryo formation frequency (\%), that is, number of embryos formed per 100 caryopsis dissected. The caryopses formed in wheat $\mathrm{x}$ maize crosses are almost invariably lacking the endosperm. Selfed caryopses formed in some of the emasculation techniques, were detected on basis of endosperm formation, and their percentage in total caryopses formed was worked out as another efficacy parameter. Different emasculation methods were compared based on above mentioned parameters. Experiment had been set up using completely randomized design. Analysis of variance was performed using Web Agri Stats Package 2.0 (http://icargoa.res.in/wasp2.0/index.php). 


\section{Results and Discussion}

The real gain from using rapid emasculation techniques would be in terms of saving in time and labour which is implicit in their very description. Thus, if any of the rapid methods showed caryopsis and embryo formation frequencies comparable to standard technique, it would be worth adopting. Results obtained from the experiment conducted during 201415 main season are summarized in table 1 . Two of the emasculation techniques used in this experiment represented standard techniques- one for wheat $\mathrm{x}$ maize crosses and the other for wheat $\mathrm{x}$ wheat crosses (clipped glume facilitated emasculation) while the third method represented a modification of the standard method. Analysis of variance showed that the variation due to emasculation methods was significant for both caryopsis and embryo formation frequency. The standard technique for wheat $\mathrm{x}$ maize crosses (emasculation of spikelets with intact glumes) showed highest mean caryopsis formation frequency $(76.91 \%)$ as well as embryo formation frequency $(37.17 \%)$.

This also endorses the utility of this method for wheat $\mathrm{x}$ maize crosses even if much greater labour and expertise are needed. The use of crossing technique generally followed for wheat $\mathrm{x}$ wheat crosses (clipped glume facilitated emasculation) proved detrimental for wheat $\mathrm{x}$ maize crosses in terms of caryopsis as well as embryo formation. Early pollinations on non-emasculated spikes fared better than clipped glume method for caryopses and embryo formation. Though the frequencies were lower than standard method (the reduction was to the tune of $24.95 \%$ in caryopsis frequency and $10.84 \%$ for embryo formation frequency), the emasculation step was completely bypassed providing significant relief in time and labour. Selfed seed formation was however observed $5.57 \%$ ). As the crop season advances, this frequency is likely to rise due to higher ambient temperature. While this method holds promise for field based crosses, detachment of the tiller tends to trigger anthesis leading to escalation of selfed seed formation. Selfed seeds tend to draw nutrition from the tiller preferentially and often result in poorer growth of crossed caryopsis and haploid embryos.

Size of caryopsis formed in clipped glume facilitated emasculation method showed severe reduction. Reduction in size may be due to humidity stress which developing caryopses receive once glumes are cut to expose it to outside environment. Nutritional support provided by the glumes is also reduced. Reduced embryo formation frequency was observed in this method as recovery of healthy haploid embryos was greatly reduced due to poor caryopsis health.

In offseason experiment during 2015, five emasculation methods were used. Along with earlier used three methods two new methods viz. plastic bag emasculation and hot water treatment were added (table2). The results pertaining to emasculation techniques also used in previous experiment showed a consistent trend. Standard emasculation technique (intact glumes) for DH production resulted in high embryo formation frequency $(24.35 \%)$. Caryopses obtained in this method were bold in size.

Clipped glume facilitated emasculation on the other hand resulted in decrease in both caryopsis number and size of caryopsis. Embryo formation frequency was reduced severely $(10.92 \%)$. Early pollination on non emasculated ears resulted in moderate embryo formation frequency $(17.61 \%)$. Some selfed seed setting $(5.56 \%)$ was also observed. As this method omits the emasculation step with only moderate loss of efficacy in caryopsis and embryo formation, it is a good candidate 
for scaled up DH production protocol. The two new techniques evaluated in this experiment are of greater interest. Plastic bag emasculation is an innovation based on the premise that as long as anthers encounter very high humidity, dehiscence is prevented. If anthers extrude out as per their normal growth schedule and get shed outside the florets without pollen release it can serve as functional emasculation. This was targeted by maintaining ears in polythene bag at near $100 \%$ relative humidity. The results however show that this target could not be achieved as a large proportion (32.99\%) of the caryopsis formed were a consequence of selfing as inferred from presence of endosperm. Further the caryopsis formation frequency was much lower $(25.07 \%)$ than that observed for the standard method. On the positive side however embryo formation frequency was high $(23.54 \%)$ and comparable to standard method. Nevertheless overall frequency was lower than standard method but significant time saving still make it a potential method for scaling up process after further fine tuning. The final method involved hot water treatment and was based on the differential sensitivity of gametes to stress treatments. Male gametes are generally regarded to be more sensitive and identification of a differential treatment can offer a means of easy emasculation. Hot water treatment used in the present study was based on the report of Hussein et al., (2012). This method resulted in a lowering of caryopsis formation frequency $(27.79 \%)$ as compared to the standard method $(46.60 \%)$. Unlike plastic bag method the selfed seed formation frequency (3.2\%) was not very high. It is indicated that the treatment is leading to loss of some of the female gametes as well. Surprisingly, this method resulted in an embryo formation frequency $(30.88 \%)$ which was higher than the standard technique (24.35\%). The overall potential for embryo formation per 100 florets $(11.4 \%)$ was only slightly lower than the standard method $(8.64 \%)$. This technique thus holds tremendous promise for hiking up DH production in a cost effective and feasible manner.

Table.1 Efficacy parameters observed for three methods of emasculation in 2014-15 crop season

\begin{tabular}{|l|c|c|c|c|}
\hline $\begin{array}{l}\text { Efficacy } \\
\text { Parameters }\end{array}$ & $\begin{array}{c}\text { No of florets } \\
\text { pollinated }\end{array}$ & $\begin{array}{l}\text { Caryopsis } \\
\text { formation } \\
\text { frequency }\end{array}$ & $\begin{array}{c}\text { Selfed seed } \\
\text { formation } \\
\text { frequency }\end{array}$ & $\begin{array}{c}\text { Embryo } \\
\text { formation } \\
\text { frequency }\end{array}$ \\
\hline $\begin{array}{l}\text { Standard } \\
\text { technique for } \\
\text { wheat x maize } \\
\text { crosses }\end{array}$ & 940 & 76.91 & 0 & 37.17 \\
\hline $\begin{array}{l}\text { Early } \\
\text { pollinations on } \\
\text { non- } \\
\text { emasculated } \\
\text { spikes }\end{array}$ & 1120 & 51.96 & 5.57 & 26.33 \\
\hline $\begin{array}{l}\text { Clipped glume } \\
\text { facilitated } \\
\text { emasculation }\end{array}$ & 960 & 46.56 & & \\
\hline CD & - & 13.26 & - & 13.63 \\
\hline
\end{tabular}


Table.2 Efficacy parameters observed from five different methods of emasculations in 2014 off season Keylong

\begin{tabular}{|c|c|c|c|c|}
\hline $\begin{array}{c}\text { Efficacy } \\
\text { Parameters }\end{array}$ & $\begin{array}{c}\text { No of florets } \\
\text { pollinated }\end{array}$ & $\begin{array}{c}\text { Caryopsis } \\
\text { formation } \\
\text { frequency }\end{array}$ & $\begin{array}{c}\text { Selfed seed } \\
\text { formation } \\
\text { frequency }\end{array}$ & $\begin{array}{c}\text { Embryo } \\
\text { formation } \\
\text { frequency }\end{array}$ \\
\hline $\begin{array}{c}\text { Standard } \\
\text { technique for } \\
\text { wheat x maize } \\
\text { crosses }\end{array}$ & 560 & 46.60 & 0 & 24.35 \\
\hline $\begin{array}{c}\text { Early } \\
\text { pollinations on } \\
\text { non- } \\
\text { emasculated } \\
\text { spikes }\end{array}$ & 550 & 44.90 & 5.56 & 17.61 \\
\hline $\begin{array}{c}\text { Clipped glume } \\
\text { facilitated } \\
\text { emasculation }\end{array}$ & 640 & 16.40 & 0 & \\
\hline $\begin{array}{c}\text { Plastic bag } \\
\text { emasculation }\end{array}$ & 630 & 25.07 & 33.99 & 23.54 \\
\hline $\begin{array}{c}\text { Hot water } \\
\text { emasculation }\end{array}$ & 590 & 27.79 & 3.20 & 30.88 \\
\hline CD & - & 6.8 & - & 2.88 \\
\hline
\end{tabular}

The idea that conventional crossing techniques used in wheat may not be suitable in case of wheat $x$ maize crosses, because of greater genetic distance involved, lead to the efforts towards development of modified techniques. Laurie and Bennett (1988) modified the crossing techniques in such a way that one of the primary florets was cross pollinated and other were allowed to selfpollinate.

They found that the percentage recovery of embryos was more in the case of selfpollinated /cross pollinated spikelets (i.e., modified method). Techniques used in the present study have an element of nondeliberate selfing, though its specific benefits are not a target. Easy sorting of selfed and crossed seeds permits the occurrence of some selfing without serious setback to overall efficacy. In another study, Laurie (1989) showed that keeping glumes of emasculated florets intact gave a higher fertilization frequency. The importance of keeping glumes intact was also emphasized by Kaur (2004). This has become the standard procedure for wheat $\mathrm{x}$ maize crosses and its superiority for caryopsis and embryo formation is borne out by the present study as well.

It is however the labour and time consuming aspect of this methodology which the present study aims at overcoming. Matzk and Mahn (1994) and Suenaga et al., (1997) investigated several emasculation methods in order to reduce the labour involved in wheat haploid production. They found that pollinations without emasculation gave a response that was comparable to that obtained by the standard methods used earlier involving emasculation of spikelets. Sandhu et al., (2002) tried the use of chemical hybridizing agents (CHAs) for facilitating wheat $\mathrm{x}$ maize crosses. They found that though in some cases 
the crossed seed formation was at par with the standard methods, but still CHAs cannot be used due to drastically lowered haploid formation frequency, probably due to phytotoxic effects of CHA. Another study by Sandhu et al., (2003) investigated various rapid crossing techniques. They used three methods: unemasculated clipped florets, emasculated clipped florets and emasculated unclipped florets for making wheat $\mathrm{x}$ maize crosses at Keylong (H.P.) and found these three to be at par in terms of haploid formation and plant regeneration.

Later work showed that the clipped florets technique could be used only on off season location (Keylong) due to more conducive grain filling conditions. Hussein et al., (2012) reported that embryo formation on hot water emasculated ears was $10.53 \%$. In the present hot water treatment gave even better results, showing high embryo formation frequency and low selfing percentage. The embryos showed normal regeneration (data not presented here). This method is an excellent candidate for replacement of manual emasculations particularly in combination with detached tiller culture technique. Further research work particularly for lowering female gamete sterility with this method is being carried out.

\section{References}

http://icargoa.res.in/wasp2.0/index.php (2015) Hussain M, Niaz M, Iqbal M, Iftikhar T and Ahmad J (2012) Emasculation techniques and detached tiller culture in wheat x maize crosses. J Agril Res 50:119.

Jensen C J (1977) Monoploid production by chromosome elimination. In: Reinert $\mathbf{J}$ and Bajaj Y P S (ed) Applied and Fundamental Aspects of Plant Cell Tissue and Organ Culture. Pp 299-340.
Springer-Verlag, New York.

Kaur H (2004) Development of methods for high frequency haploid production in wheat using wheat $x$ maize crosses. M.Sc. thesis, Punjab Agricultural University, Ludhiana, India.

Kuchel H, Ye G, Fox G and Jefferies S (2005) Genetic and economic analysis of a targeted marker- assisted wheat breeding strategy. Mol Breeding 16:6778.

Laurie D A (1989) Factors affecting fertilization frequency in crosses of Triticum aestivum cv. Hinghbury and Zea mays cv Seneca 60. Pl Breed 103: 133-40.

Laurie D A and Bennett M D (1986) Wheat x maize hybridization. Can J Genet Cytol 28:313-16.

Laurie D A and Bennett M D (1988) The production of haploid wheat plants from wheat $\mathrm{x}$ maize crosses. Theor Appl Genet 76: 393-97.

Matzk F and Mahn A (1994) Improved techniques for haploid production in wheat using chromosome elimination. Pl Breed 113: 125-29.

Murashige T and Skoog F (1962) A revised medium for rapid growth and bio assays with tobacco tissue cultures. Physiol plantarum 15: 473-97.

Sandhu A P S, Dhawan R, Gill M S and Bains N S (2002) Wheat x Maize Crosses using chemical hybridizing agents. Crop Improv 29: 154-59.

Sandhu A P S, Dhawan R, Gill M S and Bains N S (2003) Evaluation of rapid crossing techniques for haploid production in wheat $x$ maize crosses. Indian J. Genet 63: $155-56$.

Suenaga K, Marschedi A R and Darvey N L (1997) Haploid production of Australian wheat (Triticum aestivum L.) cultivars through wheat $\mathrm{x}$ maize (Zea mays L.) crosses. Aust J Agri Res 48: 1207-11. 


\section{How to cite this article:}

Gagandeep Singh, Puja Srivastava and G. S. Mavi. 2020. Comparative Evaluation of Rapid Crossing Techniques for Wheat $\mathrm{x}$ Maize System of Doubled Haploid Production. Int.J.Curr.Microbiol.App.Sci. 9(07): 189-196. doi: https://doi.org/10.20546/ijcmas.2020.907.022 